Syntax Literate: Jurnal Ilmiah Indonesia p-ISSN: 2541-0849 e-ISSN: 2548-1398

Vol. 6, No. 3, Maret 2021

\title{
MODEL KOMUNIKASI TERAPEUTIK PERAWAT PADA PASIEN SKIZOFRENIA DI RUMAH SAKIT JIWA TAMPAN PROVINSI RIAU
}

\author{
Novi Dini Restia
}

Universitas Riau, Indonesia

Email: novidinirestya@gmail.com

\begin{abstract}
The purpose of this study was to describe and analyze the therapeutic communication process and methods of nurses in the recovery process of schizophrenia patients. In this study the athors used a case study method. The research was conducted using non-partisipant observation, in depth intervieews and documentation, followed by data analysis techniques, namely data reduction, data presentation, and drawing conclusions. The result showed that the therapeutic communication model used by nurses in schizoprhenia patient is an interpersonal model and medical model. The interpersonal model used by nurses in schizophrenic patients is in the form of empathy, positive attention, and sincere acceptance, which is shown by nurses to foster trust and openness of petiens to nurses so that they can improve recovery in patients using therapeutic communication stage and thrapeutic communications methods. The medical model inused by nurses in schizofrenia patients are pharmacological, somatic therapy and ECT therapy (Electroconvulsive Therapy). The conclution in this study is that the interpersonal model and the medical model used by nurses in schizofrnic patients at the Tampan Mental Hospital in Riau Province are effective and have succeeded in improving recovery in schizofrenic patients by using therapeutic communications stage, namely preinteraction, orientation, work, and termination, and therapeutic communication methods, namely assessment, nursing diagnosis, planning, implementation, and evaluation.
\end{abstract}

Keywords: communication model; therapeutic communication; nurses; schizophrenia

\begin{abstract}
Abstrak
Tujuan penelitian ini adalah untuk mendeskripsikan dan menganalisis proses dan metode komunikasi terapeutik perawat pada pasien skizofrenia di Rumah Sakit Jiwa Tampan Provinsi Riau. Penelitian ini menggunakan metode studi kasus. Penelitian dilakukan dengan teknik pengumpulan data yaitu observasi non partisipan, wawancara mendalam dan dokumentasi, dilajutkan dengan teknik analisis data yaitu reduksi data, penyajian data dan penarikan kesimpulan. Hasil penelitian adalah Model komunikasi terapeutik yang digunakan perawat pada pasien skizofrenia di Rumah Sakit Jiwa Tampan Provinsi Riau adalah model interpersonal dan model medikal. Model interpersonal yang digunakan perawat pada pasien skizofrenia dalam bentuk sikap empati, perhatian yang positif, dan menerima dengan tulus yang ditunjukkan perawat menumbuhkan kepercayaan dan sikap terbuka pasien pada perawat sehingga dapat meningkatkan pemulihan pada pasien menggunakan tahapan komunikasi terapeutik dan metode komunikasi terapeutik. Model medikal yang
\end{abstract}


digunakan perawat pada pasien skizofrenia dalam bentuk farmakologis, terapi somatik, dan terapi ECT (ElectroConvulsive Therapy). Kesimpulan pada penelitian ini adalah model interpersonal dan model medikal yang digunakan perawat pada pasien skizofrenia di Rumah Sakit Jiwa Tampan Provinsi Riau berjalan efektif dan berhasil meningkatkan pemulihan pada pasien dengan menggunakan tahapan komunikasi terapeutik yaitu pra interaksi, orientasi, kerja dan terminasi, serta menggunakan metode komunikasi terapeutik yaitu pengkajian, diagnosa keperawatan, perencanaan, implementasi, dan evaluasi.

Kata Kunci: model komunikasi; komunikasi terapeutik; perawat; skizofrenia

Coresponden Author

Email: novidinirestya@gmail.com Artikel dengan akses terbuka dibawah lisensi

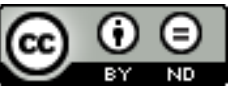

\section{Pendahuluan}

Skizofrenia didefenisikan (Iyus \& Sutini, 2016), sebagai penyakit neurologi yang mempengaruhi persepsi, cara berpikir, bahasa, emosi, dan perilaku sosial pasien yang dapat membahayakan dirinya sendiri dan orang lain. Berdasarkan data dari World health Organization 2016, skizofrenia diderita sekitar 21 juta orang.. Dapartement Kesehatan RI mencatat bahwa 70 persen gangguan jiwa terbesar di Indonesia adalah skizofrenia dan 99 persen pasien yang dirawat di rumah sakit jiwa adalah pasien skizofrenia (Arif, 2006). Berdasarkan Riset Kesehatan Dasar RI, prevalensi skizofrenia adalah 1,7 per 1.000 penduduk atau sekitar 400.000 orang.. Departemen Kesehatan menyatakan bahwa jumlah pasien skizofrenia di Provinsi Riau 1764 pasien di tahun 2017 lalu (Depkes,2017).

Data The American Psychiatric Association, menunjukkan bahwa terdapat 300 ribu pasien skizofrenia yang mengalami episode akut setiap tahun di Amerika Serikat. Pasien Skizofrenia memiliki angka kematian 8 kali lebih tinggi dari angka kematian penduduk pada umumnya, dan mencoba melakukan bunuh diri sebanyak 20-30 persen, dan 10 persen diantaranya berhasil (Iyus \& Sutini, 2016). Berdasarkan data pasien skizofrenia diagnosis keperawatan RBD (Resiko Bunuh Diri) tahun 2019 di Rumah Sakit Jiwa Tampan sendiri sudah ada 93 pasien skizofrenia yang melakukan percobaan bunuh diri, dan 7 pasien berhasil atau meninggal.

Berdasarkan observasi penulis, Ns Zaibah, Kepala Bidang Keperawatan Rumah Sakit Jiwa Tampan Provinsi Riau, mengatakan bahwa pasien gangguan jiwa di Rumah Sakit Jiwa ini termasuk jenis skizofrenia tipe paranoid dan jenis skizofrenia tipe tak terinci yang memiliki empat gejala berdasarkan diagnosa medis, yaitu halusinasi, harga diri rendah, perilaku kekerasan, dan defisit keperawatan diri. Pasien skizofrenia dengan gejala halusinasi adalah pasien yang paling sulit untuk pulih. Dan semua pasien yang memiliki empat gejala tersebut juga mengalami halusinasi.

Komunikasi yang dilakukan untuk penderita gangguan jiwa skizofrenia berbeda dengan komunikasi yang dilakukan untuk orang normal,dikarenakan keterbatasan 
kemampuan komunikasi yang dimiliki oleh pasien. Untuk dapat berkomunikasi dengan pasien skizofrenia membutuhkan sebuah teknik khusus karena pasien skizofrenia cenderung mengalami konsep diri, asyik dengan dunianya sendiri dan cenderung sehat secara fisik namun tidak dengan jiwanya. Perawat dianjurkan untuk mampu menurunkan kemampuan berkomunikasinya ketika berkomunikasi dengan pasien skizofrenia sehingga perawat dapat memposisikan dirinya dan dapat berpikir dengan perspektif yang sama serta dapat memberikan umpan balik yang tepat (Kartikasari, Idarahyuni, \& Fatharani, 2019). Mengetahui kondisi pasien tersebut maka timbulah pertanyaan tentang bagaimana sebenarnya para perawat melakukan pendekatan komunikatif terhadap pasien yang memiliki kondisi emosisonal yang tidak stabil, psikologis yang tidak kondusif dan pola pikir yang dipenuhi dengan halusinasi agar pasien mau mengikuti arahan perawat dalam tindakan asuhan keperawatannya. Contohnya, bagaimana cara perawat bisa mengajak pasien skizofrenia yang tengah sibuk dengan dunianya sendiri agar pasien mau mengalihkan dunianya dengan berinteraksi dengan perawat dan orang lain.

Salah satu bidang ilmu komunikasi yang mempelajari tentang komunikasi untuk kepentingan terapi pasien adalah komunikasi terapeutik (Kartikasari et al., 2019). Komunikasi terapeutik adalah komunikasi yang dilakukan secara sadar, bertujuan dan kegiatan dipusatkan untuk kesembuhan pasien (Purwanto et al., 2003). Komunikasi terapeutik adalah komunikasi yang mendorong proses penyembuhan klien (Depkes, 2010). Komunikasi terapeutik merupakan media utama yang digunakan untuk mengaplikasikan proses keperawatan dalam lingkungan kesehatan jiwa. Keterampilan perawat dalam komunikasi terapeutik mempengaruhi keefektifan banyak intervensi dalam keperawatan jiwa (Afnuhazi, 2015). Dalam proses komunikasi terapeutik ini akan menjelaskan mengenai berbagai model komunikasi yang dilakukan oleh perawat, agar komunikasi yang dilakukan berjalan efektif dan efisien dengan pasien (Hidayat, 2019). Model adalah cara untuk menunjukkkan sebuah objek yang di dalamnya dijelaskan kompleksitas suatu proses, pemikiran, dan hubungan antara unsur-unsur yang mendukungnya (Fisher, 1986). Sedangkan model komunikasi menurut Sereno dan Mortense adalah deskripsi ideal mengenai apa yang dibutuhkan untuk terjadinya komunikasi; model komunikasi mempresentasikan secara abstrak ciri-ciri pnting serta menghilangkan rincian komunikasi yang tidak perlu dalam dunia nyata (Mulyana, 2013).

Model komunikasi adalah deskripsi sebuah hubungan yang terbentuk dari beberapa unsur yang saling berkaitan dan melengkapi satu sama lain dan bertujuan untuk memberikan gambaran terkait proses dan metode komunikasi yang sedang terjadi. Dalam penelitian ini yaitu proses dan metode komunikasi terapeutik antara perawat dan pasien skizofrenia di Rumah Sakit Jiwa Tampan Provinsi Riau. Menurut (Mulyana, 2013), konsep model komunikasi terapeutik dalam keperawatan jiwa ada enam, yaitu Psychoanalytical, Interpersonal, Social, Existensial, Supportive Therapy, dan Medical (Afnuhazi, 2015). 
Komunikasi terapeutik secara jelas dapat ditemukan praktiknya di sebuah tempattempat pelayanan kesehatan, salah satunya yaitu rumah sakit, karena perawat di rumah sakit harus memiliki kemampuan berkomunikasi dengan pasien. Komunikasi terapeutik untuk pasien skizofrenia ditemukan praktiknya disebuah rumah sakit khusus, yaitu Rumah Sakit Jiwa yang menangani semua permasalahan pasien yang mengalami gangguan jiwa. Penelitian ini memfokuskan pada proses dan metode komunikasi terapeutik yang dilakukan perawat dan pasien skizofrenia yang di rawat di Rumah Sakit Jiwa Tampan, Provinsi Riau. Rumah Sakit Jiwa Tampan Provinsi Riau adalah rumah sakit negeri kelas A yang beralamat di Jalan H.R. Subrantas Km. 125, Kelurahan Simpang Baru, Kecamatan Tampan, Panam, Pekanbaru,Provinsi Riau. Rumah sakit ini mampu memberikan pelayanan dokter spesialis dan subspesialis luas oleh pemerintah ditetapkan sebagai rujukan tertinggi atau disebut pula sebagai rumah sakit pusat di Provinsi Riau. Seluruh pasien skizofrenia di Provinsi Riau di rawat di Rumah Sakit Jiwa Tampan. Jumlah pasien skizofrenia di tahun 2017 sebanyak 1120 khusus pasien rawat inap, dan mengalami penurunan pada tahun 2018 yang hanya mencapai 1095 pasien. Kemudian pada tahun 2019 terdapat 1041 pasien skizofrenia rawat inap di Rumah Sakit Jiwa Tampan Provinsi Riau.

Tabel 1

Data Penurunan Jumlah Pasien Skizofrenia di Rumah Sakit Jiwa Tampan Provinsi Riau 2017-2019

\begin{tabular}{ll}
\hline Tahun & Jumlah \\
\hline 2017 & 1120 \\
\hline 2018 & 1095 \\
\hline 2019 & 1041 \\
\hline
\end{tabular}

Sumber: Rekam Medik RSJ Tampan Provinsi Riau

Berdasarkan observasi, pasien skizofrenia tersebut dirawat di ruangan yang berbeda. Terdapat 7 ruangan rawat inap pasien skizofrenia di Rumah Sakit Jiwa Tampan, Provinsi Riau, yaitu:

Tabel 2

Jumlah Pasien Rawat Inap dan Jumlah Perawat Berdasarkan Ruangan Keperawatan Skizofrenia Di Rumah Sakit Jiwa Tampan Provinsi Riau Tahun 2019

\begin{tabular}{|c|c|c|c|}
\hline No & Ruangan & Jumlah Pasien & Jumlah Perawat \\
\hline 1 & Intrmediet Indragiri (Perempuan) & 46 & 15 \\
\hline 2 & Intermediet Siak (Perempuan) & 35 & 14 \\
\hline 3 & Intermediet Kuantan (Laki-laki) & 43 & 16 \\
\hline 4 & Intermediet Sebayang (Laki-laki) & 42 & 15 \\
\hline 5 & Intermediet Kampar (Laki-laki) & 30 & 15 \\
\hline 6 & Intermediet Rokan (Laki-laki) & 17 & 15 \\
\hline 7 & $\begin{array}{l}\text { UPIP (Unit Perawatan } \\
\text { Intensiv } \\
\text { Psikiatr })(\mathrm{PR} / \mathrm{LK})\end{array}$ & 828 & 21 \\
\hline & Total & 1041 & 111 \\
\hline
\end{tabular}

Sumber: Kepala Bidang Keperawatan RSJ Tampan Provinsi Riau 
Data dari Kepala Bidang Keperawatan Rumah Sakit Jiwa Tampan Provinsi Riau menunjukkan bahwa jumlah perawat di Rumah Sakit Jiwa Tampan Provinsi Riau sangat terbatas jika dilihat dari jumlah pasien yang mencapai angka seribu pada tahun 2019. Berdasarkan latar belakang yang telah dipaparkan, hal tersebut menjadi indikator untuk mengangkat sebuah penelitian dengan judul "Model Komunikasi Terapeutik Perawat pada Pasien Skizofrenia di Rumah Sakit Jiwa Tampan Provinsi Riau".

Kajian terdahulu yang digunakan penulis sebagai pendukung dalam penelitian ini ada lima, yaitu pertama penelitian tesis oleh (Pasaribu, 2014), mahasiswa magister Ilmu Komunikasi, UNS, Surakarta, 2014 dengan judul "Pola Komunikasi Terapeutik Antara Perawat-Pasien dalam Proses Penyembuhan Penderita Skizofrenia di Rumah Sakit Jiwa Daerah Dr. RM. Soedjarwadi Klaten”. Kedua penelitian oleh (Salmaniah, 2016) mahasiswa pascasarjana,Univetas Islam Negeri Sumatera Utara, 2016 dengan judul "Komunikasi Terapeutik Dokter dan Paramedis Terhadap Kepuasan Pasien Dalam Pelayanan Kesehatan Pada Rumah Sakit Bernuansa Islami Di Kota Medan". Ketiga penelitian oleh (Agnena, 2015), jurnal Ilmu Komunikasi 2015. Judul penelitiannya adalah "Analisa Komunikasi Terapeutik Dokter Dan Pasien Dalam Meningkatkan Pelayanan Kesehatan Ibu Di Rumah Sakit Aisyiyah Samarinda". Keempat penelitian oleh (Nurgustianty, 2017), mahasiswa magister Ilmu Komunikasi, Universitas Pasundan, Bandung, 2017. Judulnya adalah "Pola Komunikasi Terapeutik Perawat Pada Pasien Skizofrenia dalam Proses Penyembuhan di Klinik Jiwa Utama Grha Atma Bandung”. Kelima penelitian oleh (Witojo \& Widodo, 2008), Jurnal Berita Ilmu Keperawatan ISSN 1979-2697, Vol . 1 No.1, 2008. Judul penelitian adalah "Pengaruh Komunikasi Terapeutik Terhadap Penurunan Tingkat Perilaku Kekerasan Pada Pasien Skizofrenia Di Rumah Sakit Sakit Jiwa Daerah Surakarta”.

Tujuan dalam penelitian ini adalah untuk mendeskripsikan dan menganalisis proses komunikasi terapeutik yang dilakukan perawat dalam tindakan asuhan keperawatan pada pasien skizofrenia dan untuk mendeskripsikan dan menganalisis metode komunikasi terapeutik perawat dalam tindakan asuhan keperawatan pada pasien skizofrenia di Rumah Sakit Jiwa Tampan, Provinsi Riau. Manfaat daam penelitian ini adalah penelitian ini dapat dijadikan sebagai sumber acuan mengenai komunikasi terapeutik dan memperoleh data empiris tentang model komunikasi terapeutik perawat pada pasien skizofrenia serta dapat menjadi bahan masukan dan informasi kepada semua pihak Rumah Sakit Jiwa khususnya Rumah Sakit Jiwa Tampan Provinsi Riau dalam menggunakan komunikasi terapeutik sebagai teknik paling efektif pada proses pemulihan pasien gangguan jiwa.

\section{Metode Penelitian}

Metode yang digunakan dalam penelitian ini adalah metode kualitatif. Lokasi penelitian yang dipilih oleh penulis adalah di Kota Pekanbaru Provinsi Riau secara administratif berada di Ibu Kota Provinsi Riau dengan pertimbangan yaitu; Pertama, lokasi ini banyak terdapat bangunan, perumahan maupun pertokoan yang berdiri memiliki dan tanpa memiliki izin mendirikan bangunan yang tidak memiliki sumur air 
resapan sesuai prosedur yang sudah ditetapkan. Kedua, di lokasi ini masih banyak ditemukan pemilik bangunan yang tidak tahu tentang sumur air resapan. Penelitian ini menggunakan metode penelitian kualitatif, sesuai dengan pendapat Iskandar bahwa alasan menggunakan penelitian kualitatif karena tujuan penelitian adalah untuk memahami peristiwa yang tersembunyi di balik fenomena nyata atau reality. Penulis menggunakan penelitian kualitatif juga untuk mendeskripsikan dan menganalisis secara mendetail bagaimana model komunikasi terapeutik yang digunakan perawat pada pasien skizofrenia dalam tindakan asuhan keperawatan, selain itu penulis juga ingin mendeskripsikan dan menganalisi proses dan metode komunikasi terapeutik perawat pada pasien skizofrenia, serta ingin mengtahui cara pandang perawat terhadap pasien skizofrenia lebih mendalam yang tidak dapat diwakili dengan pola-pola statistik mengenai komunikasi yang dijalankan bersama pasien skizofrenia. Upaya untuk mendapatkan data yang valid, reliable, dan objektif tentang fenomena-fenomena yang berlaku akan lebih mudah untuk didapatkan melalui metode ini karena penulis dapat menentukan jenis data yang diinginkan. Melalui pengamatan, wawancara, dokumentasi, seperti foto, gambar, serta percakapan informal terhadap narasumber atau informan, fenomena yang diamati dapat dideskripsikan lebih utuh, lengkap dan sebagaimana adanya. Pemilihan informan dalam penelitian ini menggunakan teknik Purposive Sampling yang mana penentuan informan berdasarkan pertimbangan bahwa informan yang dipilih adalah orang-orang yang mengetahui dan terlibat dalam dan telah di tentukan sebelumnya. Untuk mendapatkan data penulis melakukan observasi desktiftif dan juga wawancara secara mendalam pada informan yaitu lima perawat, dua pasien skizofrenia yang sudah tenang dan satu security Rumah Sakit Jiwa Tampan.

\section{Hasil dan Pembahasan}

Model komunikasi terapeutik yang digunakan perawat pada pasien skizofrenia di Rumah Sakit Jiwa Tampan Provinsi Riau adalah model komunikasi interpersonal dan model Medical. Model komunikasi terapeutik yang digunakan perawat pada pasien skizofrenia di Rumah Sakit Jiwa Tampan Provinsi Riau adalah model interpersonal dan model medical. Model interpersonal digunakan dalam proses komunikasi terapeutik dengan tujuan untuk membangun komunikasi yang efektif pada pasien skizofrenia.

Dalam model interpersonal yang digunakan perawat sebagai model komunikasi terapeutik pada tindakan asuhan keperawatan di Rumah Sakit Jiwa Tampan Provinsi Riau menunjukkan sikap empati, perhatian, positif, dan menerima dengan tulus dari perawat kepada pasien yang dapat memberikan pasien rasa percaya dan sikap terbuka dengan perawat, sehingga perawat dapat membantu mengatasi permasalahan pasien, dengan kepercayaan dan sikap terbuka yang diberikan pasien pada perawat, pasien akan mudah menerima tindakan asuhan keperawatan yang dilakukan perawat untuk pemulihan pada pasien dalam proses komunikasi terapeutiknya. Model medical digunakan perawat dalam tindakan asuhan keperawatan pada pasien skizofrenia di Rumah Sakit Jiwa Tampan Provinsi Riau dalam bentuk tindakan medis berupa pemeriksaan diagnostik, terapi somatik, . terapi ECT (Electroconvulsive Therapy), 
farmakologik, dan teknik interpersonal. Untuk itu, di Rumah Sakit Jiwa Tampan ini, perawat berperan dalam berkolaborasi dengan tim medis melakukan prosedur diagnostik dan terapi jangka panjang atau rawat inap.

Skizofrenia dibagi menjadi lima jenis yaitu,tipe paranoid, tipe hebefrenik atau yang tidak terorganisir, tipe katatonik, tipe tak terinci, dan tipe residual. Jenis skizofrenia di Rumah Sakit Jiwa Tampan Provinsi Riau adalah jenis skizofrenia paranoid dan tipe tak terinci. Dan kedua jenis skizofrenia tersebut mengalami gejala halusinasi pendengaran, penglihatan dan perabaan yang bertahap Skizofrnia tipe paranoid adalah jenis skizofrenia yang mengalami halusinasi pendengaran, seperti mendengar suara-suara,hal itu yang membuat pasien kehilangan kendali sehingga bisa membahayakan dirinya sendiri dan orang disekitarnya. Skizofrenia tipe tak terinci adalah jenis skizofrenia yang memilki gangguan perilaku yang lebih dari satu, tipe tak terinci juga mengalami halusinasi.

Semua jenis skizofrenia yang ada di Rumah Sakit Jiwa Tampan ini mengalami halusinasi pendengaran dan penglihatan, namun jenis skizofrnia tipe paranoid merupakan jenis skizofrenia dimana pasiennya mengalami hal-hal diluar kendalinya dan melakukaan hal-hal yang dapat mencelakai orang disekitarnya bahkan dirinya sendiri. Perubahan perilaku yang sangat dramatis terjadi dalam beberapa hari atau minggu. Serangan yang mendadak selalu memicu terjadinya periode akut secara cepat. Berdasarkan hasil penelitian,, bahwa dalam beberpa kasus skizofrenia di Ruamh Sakit Jiwa Tampan, pasien skizofrenia kronis atau paranoid, menjadi buas, kehilanagn karakter sebagai manusia dalam kehidupan sosial, tidak memiliki motivasi sama sekali, depresi, dan tidak memilki kepekaan tentang perasaannya sendiri, bahkan sampai pada tindakan yang membahayakan sekitar dan dirinya sendiri.

Proses komunikasi terapeutik terhadap pasien skizzofrenia di Rumah Sakit Jiwa Tampan Provinsi Riau dilakukan dari awal pasien masuk ke Rumah Sakit Jiwa yang pertama kali langsung ditangani oleh perawat yang bertugas di Ruang IGD. Kemudian dilakukan penanganan medis berupa injeksi untuk pasien yang mengalami amukan berat dan dengan perilaku yang tidak bisa dikendalikan, selanjutnya perawat bekerja sama dengan dokter spesialis patologi psikiatri untuk pengecekan kondisi fisik pasien melalui teknologi ct scan bagian kepala. Lalu perawat mencatat data diri pasien dari pihak keluarga pasien yang mengantar ke Rumah Sakit Jiwa. Perawat membuat kontrak dengan pihak keluarga pasien untuk melakukan pertemuan pada waktu yang ditentukan oleh perawat mengenai informasi tentang pasien untuk kelengkapan data yang diperlukan perawat dalam tindakan asuhan keperawatan yang akan dilaksanakan selanjutnya.

Setelah dilakukan penanganan medis, pasien dipindahkan ke ruangan UPIP (Unit Perawatan Intensiv Psikiatri). Di ruangan UPIP, pasien di pantau kondisi kesehatannya oleh perawat. sampai pada kondisi pasien sadar dan agak tenang, pasien diberi obat sesuai dosis yang dibutuhkan. Jika didapati kondisi pasien sudah sadar namun menolak untuk tidak minum obat, maka perawat akan tetap memberikan pasien obat dengan bantuan penanganan oleh security. Setelah kondisi pasien dipastikan sudah tenang, 
perawat baru kemudian bisa melakukan tahapan komunikasi terapeutik selanjutnya pada pasien sesuai dengan metode komunikasi terapeutik yang digunakan dalam tindakan asuhan keperawatan yaitu pengkajian, diagnosa keperawatan, perencanaan, implementasi dan evaluasi melalui tahap pra interaksi, tahap orientasi, tahap kerja dan tahap terminasi.

\section{Bagan 1}

Proses Komunikasi Terapeutik Perawat pada Pasien Skizofrenia di Rumah Sakit Jiwa Tampan Provinsi Riau.

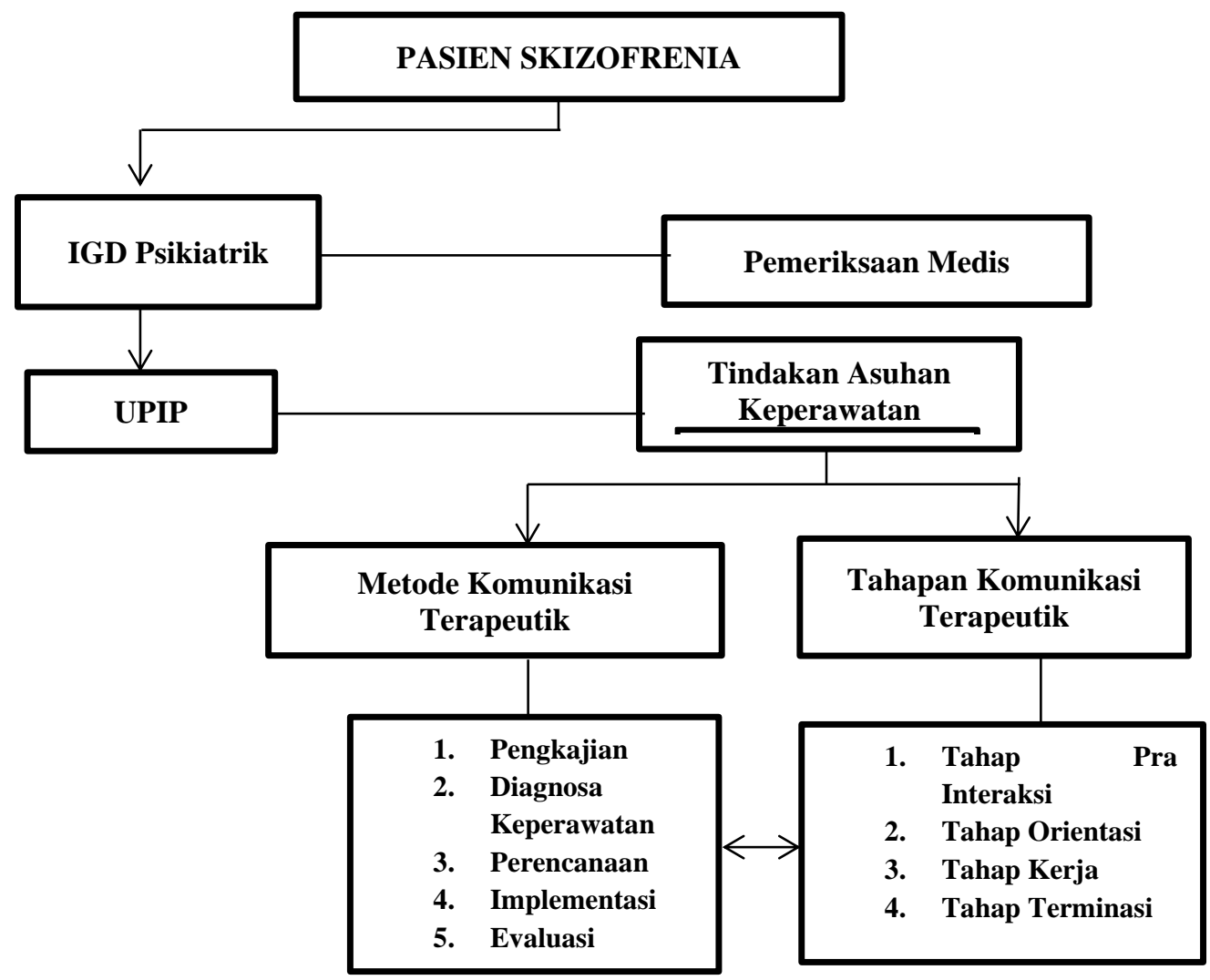

Sumber: Hasil Penelitian

Tahapan Komunikasi Terapeutik Perawat pada Pasien Skizofrenia di Rumah Sakit Jiwa Tampan Provinsi Riau

1. Tahap Pra Interaksi

Pada tahap ini perawat harus bisa mengontrol perasaannya untuk tidak memilki prasangka buruk kepada pasien, karena hal itu dapat mengganggu hubungan saling percaya. Perawat harus peka terhadap kebutuhan-kebutuhan pasien agar pasien merasa senang dan merasa dihargai. Tahap pra interaksi dilakukan perawat untuk memahami dirinya, mengatasi kecemasannya, dan meyakinkan diri bahwa dia benar-benar siap untuk berinteraksi dengan pasien. 


\section{Tahap Orientasi}

Langkah-langkah yang dilakukan perawat pada tahap ini adalah sebagai berikut:

a. Melaksanakan proses komunikasi dengan baik pada perkenalan dengan pasien

b. Membuat kontrak sebelum bertemu dan sesudah bertemu untuk pertemuan slanjutnya. Tujuan membuat janji terlebih dahulu agar pasien tidak terjebak dalam kondisi pasien yang sedang kurang baik, juga disesuaikan dengan kesepakatan yang dibuat bersama perawat lainnya.

c. Kegigihan dan kesabaran perawat dalam menggali informasi. Perawat harus teliti dan tidak terburu-buru dalam melakukan observasi, agar tidak ada informasi yang tertinggal dari pasien.

d. Mendengarkan dan observasi aktif.

Tahap ini juga diawali dengan perkenalan,perawat akan menanyakan tentang diri pasien. Pada tahap ini perawat dan pasien mulai mengembangkan hubungan komunikasi interpersonal yaitu dnegan memberikan salam, senyum, perawat menunjukkan keramahan kepada pasien, memperkenalkan diri, menanyakan nama pasien dan menanyakan keluhan pasien.

3. Tahap Kerja

Tahap ini tidak dapat dipisahkan dengan tahap orientasi, karena dalam proses interaksi komunikasi yang dijalin antara perawat dan pasien skizofrenia tujuannya tidak hanya sebatas pembicaraan yang menyentuh emosional saja, tetapi dapat mendorong kepada kesembuhan pasien. Seperti menyuruh minum obat, menasehati, dorongan untuk banyak melakukan interaksi dengan orang lain.

Langkah- langkah yang dilakukan perawat pada pasien dalam tahap ini adalah sebagai berikut:

a) Menggunakan intonasi yang tinggi dalam penyampaian pesan

b) Memberikan pengertian tentang manfaat-manfaat berinteraksi dengan sesama

c) Melakukan kegiatan-kegiatan sebagai solusi dari masalah pasien

d) Jangan memaksakan kehendak

4. Tahap Terminasi

Pada tahap ini tidak sepenuhnya pasien skizofrnia bisa sembuh total atau kembali normal, akan tetapi tahap ini dapat mengurangi tingkat tekanan psikis pasien dengan interaksi komunikasi yang dilakukan secara intens dan pengobatan yang rutin.

Berdasarkan hasil wawancara bahwa pasien skizofrenia tidak sepenuhnya bisa sembuh dan normal kembali, larena untuk konsisi pasien skizofrenia dengan klasifikasi berbagai tipe ini, bahwa kondisi psikomotorik pada dirinya yang terganggu, baik itu secara hormon dari lahir ataupun tekanan deresi dari lingkungan.

Sebelum perawat melakukan asuhan dan tindakan keperawatan, perawat mempersiapkan diri dengan membuat Strategi Pelaksanaan (SP) komunikasi. Dan apabila perawat membuat SP komunikasi, itu artinya perawat sudah memasuki fase 
pra orientasi tahapan komunikasi terapeutik dan hubungan terapeutik antara perawat dan pasien.

Tabel 1

Format Strategi Pelaksanaan (SP) Komunikasi Rumah Sakit Jiwa

Tampan Provinsi Riau

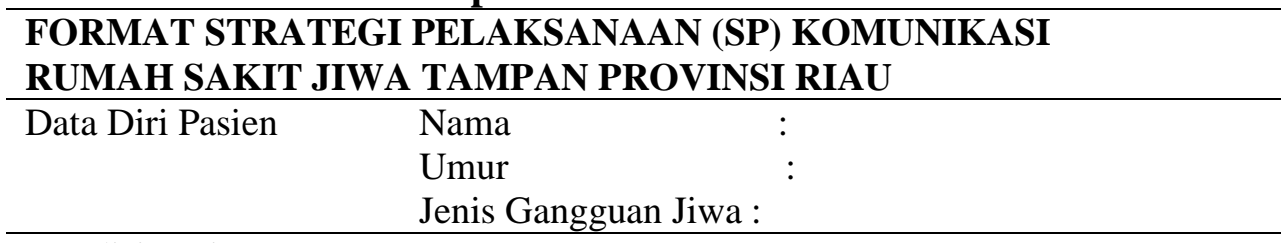

Kondisi Pasien

Diagnosa Keperawatan

Tujuan

SP Komunikasi

Tahap Orientasi :

Salam terapeutik

Evaluasi dan validasi

Tahap Kerja : : Kontrak

Tahap Terminasi : $\quad$ akan dcapai atau lakukan)

Evaluasi subjektif/objektif

Rencana tindak lanjut

Kontrak yang akan datang

\section{Sumber: Hasil dokumentasi peneliti}

Metode komunikasi terapeutik yang digunakan perawat Rumah Sakit Jiwa Tampan pada pasien skizofrenia ada empat, yaitu pengkajian, Diagnosa Keperawatan, Implementasi, dan evaluasi sebagai berikut:

a. Pengkajian

Pada pasien skizofresnia, pengkajian terjadi pada level individu, keluarga, dan lingkungan. Perawat harus sadar terhadap perubahan fisiologis, psikologis, dan persepsi pasien tanpa mengabaikan kehidupan pribadi pasien. Faktor-faktor yang perlu diperhatikan adalah situasi keidupan, dukungan keluarga, dan stres. Perawat harus tetap waspada terhadap setiap perubahan di setiap aspek kehidupan pasien karena akan dapat mempengaruhi potensi pasien untuk kambuh.

Selain itu perawat juga perlu mengidentifikasi faktor-faktor yang mempengaruhi suatu pengkajian, seperti partisipasi pasien, keadaan sehat pasien, pengalaman pasien sebelumnya terhadap pelayanan kesehatan, kemampuan belajra pasien, serta perilaku dan pendekatan yang dilakukan perawat selama proses terapeutik berlangsung. Faktor-faktor tersebut bisa mempengaruhi hasil pengkajian sehingga mempengaruhi proses terapeutik yang 
akan dilakukan seorang perawat. Oleh karena itu, untuk melangsungkan suatu pengkajian, perawat harus sadar betul dengan setiap poin hal yang akan dikaji, bukan hanya sekedar syarat dokumentasi.

Pada tahap ini perawat menggunakan kemampuan verbal maupun nonverbal dalam mengumpulkan data pasien skizofrenia. perawat juga dituntut untuk mampu melakukan pengamatan baik verbal maupun nonverbal serta menginterprtasikan hasil pengamatan dalam bentuk masalah. Setelah data terkumpul, selanjutnya dikomunikasikan dalam bahasa verbal kepada pasien atau tim medis lainnya dan dikomunikasikan dalam bentuk tulisan (di dokumentasikan) untuk selanjutnya dikomunikasikan pada tim medis lain dan sebagai aspek legal tindakan atau asuhan keperawatan.

Keterampilan komunikasi perawat pada tahap pengkajian akan sangat menentukan kelengkapan data yang diperolehnya dan akan menentukan proses selanjutnya. Adapun bentuk-bentuk komunikasi yang digunakan perawat terhadap pasien skizofrenia di Rumah Sakit Jiwa Tampan pada tahap pengkajian dalam proses komunikasi terapeutik adalah wawancara, pemeriksaan fisik, dan observasi, serta pengumpulan data melalui catatan medik ? rekam medik, dan dokumen lain yang relevan.

b. Diagnosa Keperawatan

Pada tahap diagnosa keperawatan, komunikasi yang dilakuakan perawat pada pasien untuk mengkalrifikasi data dan menganalisisnya sebelum menentukan masalah keperawatan pasien, selanjutnya mendiskusikan dengan pasien. Masalah, tanda dan gejala pasien pada diagnosa keperawatan yang telah ditetapkan dikomunikasikan atau disampaikan kepada pasien agar pasien dapat berusaha bekerjasama dengan perawat untuk mengatasi masalahnya. Hal itu juga dikomunikasikan kepada perawat lain secara langsung dan data lain berupa tulisan untuk dokumentasi. Teknik yang dilakukan pada tahap diagnosa keperawatan ini adalah teknik memberikan informasi.

c. Perencanaan

Pada tahap ini tugas perawat adalah merumuskan tujuan keperawatan dan menetapkan kriteria keberhasilan, merencanakan asuhan keperawatan, dan tindakan keperawatan yang akan dilakukan. Komunikasi yang penting dilakukan perawat pada tahap ini adalah mendiskusikan kembali rencana yang sudah disusun perawat dan bersama pasien menentukan kreteria keberhasilan yang akan dicapai. Pada tahap ini keterlibatan keluarga juga penting kaitannya dengan peran serta keluarga dalam perawatan pasien. Rencana asuhan keperawatan selanjutnya di tulis atau didokumentasikan dalam status pasien,sebagai bentuk tanggung jawab profesional dan memudahkan komunikai antar tim kesehatan untuk asuhan keperawatan yang berkesinambungan.

Komunikasi yang dilakukan perawat pada pasien yaitu dengan melakukan latihan kembali untuk mempraktekkan komunikasi terapeutik pada proses perencanaan ini, dan melakukan tahapan-tahapan komunikasi terapeutik yaitu 
meliputi fase orientasi (salam terapeutik,evaluasi-validasi, dan kontrak, fase kerja, fase terminasi (evaluasi subjektif/objektif, rencana tindak lanjut, dan kontrak yang akan datang).

d. Implementasi

Pada tahap implementasi ini perawat berkomunikasi dan diskusi dengan para profesional medis lainnya dalam rangka untuk memberikan penanganan yang tepat adekuat pada pasien. Pada tahap ini perawat sangat efektif berkomunikasi dengan pasien karena perawat akan menggunakan seluruh kemampuan dalam komunikasipada saat menjelaska tindakan tertentu, memberikan pendidikan kesehatan, konseling, menguatkan sistem pendukung membantu meningkatkan koping. Perawat menggunakan komunikasi verbal dan nonverbal selama melakukan tindakan keperawatan untuk mengetahui respon pasien secara langsung atau yang diucapkan maupun yang tidak diucapkan. Semua aktivitas keperawatan harus didokumentasikan secara tertulis untuk dikomunikaiskan kepada tim medis lainnya yang bertugas pada shief selanjutnya, mengidentifikasi rencana tindak lanjut, dan aspek legal dalam asuhan keperawatan. Teknik komunikasi yang digunakan pada tahap ini adalah memberikan onformasi dan berbagi persepsi.

Pada saat melakukan tindakan keperawatan,selain komunikasi verbal yang diucapkan dengan kata-kata, perawat menggunakan komunikasi nonverbal dalam menunjukkan sikap terapeutik secara fisik selama berkomunikasi dengan pasien, seperti ekspresi wajah menyenangkan dan tampak ikhlas sambil memberikan senyuman, mendekat dan membungkuk ke arah pasien, mempertahankan kontakmata yangmenunjukkan kesungguhan untuk membantu, sikap terbuka tidak melipat tangan atau kaki saat interaksi dengan pasien berlangsung, dan tetap rileks.

e. Evaluasi

Pada tahap evaluasi, perawat menilai keberhasilan dari asuhan dan tindakan keperawatan yang telah dilakukan. Semua hasil kemudian dicatat dalam catatan perkembangan perawatan pasien, mendiskusikan hasil dengan pasien,meminta tanggapan pasien atas keberhasilan dan tidak keberhasilan, dan bersama pasien merencanakan tindak lanjut asuhan keperawatan.jika belum berhasil maka perawat akan melakukan diskusi kembali dengan pasien apa yang diharapkan dan bagaimana peran serta atau keterlibatan pasien dan keluarga dalam mencapai tujuan dan rencana baru untuk asuhan keperawatan pasien.

Pada setiap tahap dalam proses perawatan, perawat menggunakan teknikteknik komunikasi terapeutik untukmembina hubungan intim dengan pasien mulai dari tahap orientasi, tahap kerja, dan tahap terminasi. 


\section{Kesimpulan}

Kesimpulan pada penelitian ini adalah model interpersonal dan model medikal yang digunakan perawat pada pasien skizofrenia di Rumah Sakit Jiwa Tampan Provinsi Riau berjalan efektif dan berhasil meningkatkan pemulihan pada pasien dengan menggunakan tahapan komunikasi terapeutik yaitu pra interaksi, orientasi, kerja dan terminasi, serta menggunakan metode komunikasi terapeutik yaitu pengkajian, diagnosa keperawatan, perencanaan, implementasi, dan evaluasi. 


\section{BIBLIOGRAFI}

Afnuhazi, Ridyalla. (2015). Komunikasi terapeutik dalam keperawatan jiwa. Yogyakarta: Gosyen Publishing

Agnena, Siti Aulia Kharisma. (2015). Analisa Komunikasi Terapeutik Dokter dan Pasien Dalam Meningkatkan Pelayanan Kesehatan Ibu di Rumah Sakit Aisyiyah Samarinda. e-Journal Ilmu Komunikasi vol 3 no 1.

Depkes, R. I. (2010). Standar pelayanan kebidanan. Jakarta: Kemenkes RI.

DepKes, R. I. (1993). Pedoman Penggolongan dan Diagnosis Gangguan Jiwa di Indonesia III. Jakarta Direktorat Jenderal Pelayanan Medik Departemen Kesehatan RI.(12017), 10.

Fisher, William M. (1986). Ther DARPA speech recognition research database: specifications and status. Proc. DARPA Workshop on Speech Recognition, Feb. 1986, 93-99.

Hidayat, M. Arif. (2019). Analisis Isi Siaran Berita Program "DIALOG SUMUT” di Metro Tv Sumut.

Iyus, Yosep, \& Sutini, Titin. (2016). Buku Ajar Keperawatan Jiwa. Cetakan VII. Bandung: Refika Aditama.

Kartikasari, Rina, Idarahyuni, Erna, \& Fatharani, Windya Satya. (2019). Komunikasi Terapeutik Perawat Terhadap Orang Dengan Gangguan Jiwa (ODGJ) Di Ruang Tenang Rumah Sakit Jiwa Provinsi Jawa Barat Dan Klinik Utama Kesehatan Jiwa Hurip Waluya Sukajadi Bandung Jawa Barat. Jurnal Kesehatan Aeromedika, 5(2), $1-12$.

Mulyana, Deddy M. A. (2013). Metode penelitian komunikasi: Contoh-contoh penelitian kualitatif dengan pendekatan praktis. Bandung: PT Remaja Rosdakarya.

Nurgustianty, Deby. (2017). Pola Komunikasi Terapeutik Perawat Pada Pasien Skizofrenia dalam Proses Penyembuhan di Klinik Jiwa Utama Grha Atma Bandung. Magister Ilmu Komunikasi.

Pasaribu, Rotumiar. (2014). Pola Komunikasi Terapeutik Antara Perawat-Pasien dalam Proses Penyembuhan Penderita Skizofrenia di Rumah Sakit Jiwa Daerah Dr. RM. Soedjarwadi Klaten. UNS (Sebelas Maret University).

Yamaguchi, Yasuo, \& Yamauchi, H. (2003). Preliminary Study Of Microstructure Dependence Of Magnetoresistance Behavior On Sm.-xlaxmo2ge2 Compound With X= o, lo, 3. Jurnal Mikroskopi Dan Mikroanalisis, 3(1).

Salmaniah, Nina Siti Siregar. (2016). Komunikasi Terapeutik Dokter dan Paramedis

Terhadap Kepuasan Pasien Dalam Pelayanan Kesehatan Pada Rumah Sakit 
Model Komunikasi Terapeutik Perawat pada Pasien Skizofrenia di Rumah Sakit Jiwa

Bernuansa Islami Di Kota Medan. Program Studi Komunikasi Islam Program Pascasarjana Univetas Islam Negeri Sumatera Utara Medan.

Witojo, Djoko, \& Widodo, Arif. (2008). Pengaruh Komunikasi Terapeutik Terhadap Penurunan Tingkat Perilaku Kekerasan Pada Pasien Skizofrenia Di Rumah Sakit Sakit Jiwa Daerah Surakarta. Jurnal Berita Ilmu Kperawatan.

Astikasari Ayu R, Rasianna BR Saragih, (2019). Penerapan Komunikasi Terapeutik Pelayanan Kesehatan (Studi) Komunikasi Terapeutik Dokter Spesialis Obstetri dan Ginekologi dengan Pasien Ibu Hamil pada Praktik Dokter Bersama di Apotel Al- Khair Bengkulu. Jurnal Kaganga Vol 3 No 1.

Prihati, ningsih \& Yuni Wijayanti, (2019). Gangguan Mental Emosional Siswa Skolah Dasar. Higeia Journal Of Public Health Research and Development $3(2)$.

Ayuningtyas Dumilah, \& Misnaniarti, Marisa Rayhani, (2018). Analisis Situasi Kesehatan ental pada Masyarakat Indonesia dan Strategi Intervensi. Jurnal Ilmu Kesehatan Masyarakat Vol 9 No 1.

El Fiah, Rifda \& Nilawati Tadjuddin, (2018). Pembangunan Layanan Bimbingan Kesehatan Mental di Lembaga Pendidikan Tinggi. Prosiding Konferensi Internasional Pendidikan Konseling dan Psikologi (ICONCEP) Vol 1.

Prasanti, Ditha, (2017). Komunikasi Terapeutik Tenaga Medis dalam Pemberian Informasi tentang Obat Tradisional bagi Masyarakat. Jurnal Komunikasi Mediator Vol 10 No 1.

Dyana, Utami, (2015). Komunikasi Terapeutik Dokter dan Pasien Dalam Pengobatan Homeopati di Pusat Pengobatan Al Jawab Pekanbaru. Jurnal Jom FISIP Vol 2 No 1.

Kholil, Syukur ,\& Lahmuddin Lubis, Syafruddin Ritonga, ( 2019). Implementation of Therapeutic Communication at Dr. Pirngadi Hospital. BIRCI-Journal Vol 2 No 4. 